\title{
Ressignificação do TEPT a partir da clínica psicodinâmica do trabalho
}

\author{
Ronaldo Gomes Souza' y Ana Magnólia Mendes² \\ Universidade de Brasilia (Brasil)
}

Recibido: enero 15 de 2016 - Revisado: marzo 11 de 2016 - Aceptado: mayo 24 de 2016

Referencia formato APA: Gomes-Souza, R. \& Mendes, A. M. (2016). Ressignificação do TEPT a partir da clínica psicodinâmica do trabalho. Rev. Guillermo de Ockham, 14(2), 73-82. doi: http://dx.doi.org/10.21500/22563202.2424

\section{Resumo}

As exigências da gestão neoliberal globalizante atual precarizam as relaçôes de trabalho, diminuem os direitos trabalhistas, negam a cidadania e são fontes de sofrimentos e doenças no trabalho como depressão, burnout, estresse, sobretudo o Transtorno de estresse pós-traumático (TEPT). O objetivo desse ensaio teórico é apresentar a perspectiva da clínica psicodinâmica do trabalho como possível solução dos trabalhadores ressignificarem o sofrimento patogênico do TEPT. O método da clínica psicodinâmica do trabalho consiste no processo de fala e escuta do sofrimento no trabalho. Para tal, é preciso conhecer o contexto e a organização do trabalho no qual os sujeitos adoecidos estão e criar condiçóes na relação do pesquisador-clínico com os trabalhadores adoecidos para ressignifcarem o sofrimento causado pelo TEPT no trabalho, em diferentes etapas. Conclui-se que, uma vez que se reconhece o potencial sofrimento do TEPT no contexto laboral, a Psicologia do Trabalho precisa desenvolver novas alternativas éticas e políticas de intervenção que crie condiçóes para os trabalhadores adoecidos vivenciarem situaçóes de prazer e saúde no trabalho, tal é a proposta da clínica psicodinâmica do trabalho. Novos resultados estão em processo de desenvolvimento no Clinical Psychodynamic of Work Lab. at University of Brasília para fortalecimento dessa perspectiva.

Palavras-chave: Ressignificação, TEPT, clínica psicodinâmica do trabalho

\section{PTSD's reframing using clinical psychodynamich of work}

\section{Abstract}

The requirements of the current globalizing neoliberal management decrease labor rights, denied citizenship and are a source of suffering and illnesses at work and depression, burnout, stress, particularly posttraumatic stress disorder (PTSD). The objective of this theoretical article is to present the perspective of Clinical Psychodynamic of Work as a possible solution for workers reframing pathogenic suffering from PTSD. The method of Clinical Psychodynamic of Work is the process of speaking and listening suffering at work. To do this, one must know the context and organization of work in which the workers are diseased and create conditions in researcher-clinician relationship with the sickened workers to reframe the suffering caused by PTSD at work, at different stages. In conclusion, since

1. Doutorado (em andamento) em Psicologia Social, do Trabalho e das Organizaçóes (PSTO) da Universidade de Brasília (UnB). Pesquisador no Laboratório de Psicodinâmica e Clínica do Trabalho (LPCT) da UnB. Professor da Pontifícia Universidade Católica de Goiás (PUC-GO). Email: ronaldopsicologo@hotmail.com

2. Pós-doutora em Psicologia; Professora no Programa de PSTO da UnB. Pesquisadora e Coordenadora do LPCT da UnB. Email: anamag.mendes@ gmail.com 
it recognizes the potential suffering of PTSD in the employment context, the Work Psychology must develop new ethical and intervention policy alternatives that create conditions for diseased workers to experience pleasure and health situations at work, such is the proposal of Clinical Psychodynamic of Work. New results are being developed in Clinical Psychodynamic of Work Lab. At University of Brasilia to strengthen this perspective.

Keywords: Reframing, PTSD, Clinical Psychodynamic of Work

\section{Redefinición del TEPT a partir de la clínica psicodinámica del trabajo}

\section{Resumen}

Los requisitos de la corriente neoliberal globalizadora disminuyen los derechos laborales y son fuente de sufrimientos y enfermedades en el trabajo, como el trastorno de estrés postraumático (TEPT). El objetivo de este artículo teórico es presentar la perspectiva de la clínica psicodinámica del trabajo como posible solución para que los trabajadores redefinan el sufrimiento patogénico del TEPT. El método de la clínica psicodinámica del trabajo es el proceso de hablar y escuchar el sufrimiento en este ámbito y para esta perspectiva hay que conocer el contexto y la organización del trabajo en el que los sujetos están enfermos y crear condiciones para que redefinan el sufrimiento causado por el TEPT en el trabajo, en diferentes etapas. En conclusión, ya que se reconoce el sufrimiento potencial del TEPT en el contexto laboral, la psicología del trabajo debe desarrollar nuevas políticas éticas y de intervención que creen condiciones para los trabajadores enfermos para que experimenten situaciones de placer y salud en el trabajo; tal es la propuesta de la clínica psicodinámica del trabajo. Los nuevos resultados se están desarrollando en laboratorio de la clínico psicodinámica del trabajo en la Universidad de Brasilia para fortalecer esta perspectiva.

Palabras clave: Redefinición, transtorno de estrés postraumático, clínica psicodinámica del trabajo

\section{Introdução}

O objetivo desse artigo teórico é apresentar a perspectiva da Clínica psicodinâmica do trabalho como possível solução dos trabalhadores reframe o sofrimento patogênico do Transtorno de Estresse Pós-Traumático (TEPT), criando condiçóes para os trabalhadores adoecidos vivenciarem situaçóes de prazer e saúde no trabalho. Diante do sistema político-econômico capitalista e das transformações e dinâmicas sociais vigentes, há muitas perspectivas teóricas e metodológicas que vão se esforçar para lidar com os desafios da precarizaçáo do trabalho na atualidade (Hirata, 2011). A perspectiva defendida nesse artigo é da Clínica psicodinâmica do trabalho (Mendes $\&$ Araújo, 2012). Tal perspectiva ressalta que as atividades laborais desempenham papeis fundamentais na vida humana. $\mathrm{O}$ trabalho, assim, deve ser fonte de prazer e de saúde, para que os trabalhadores sejam capazes de enfrentar as barreiras do adoecimento e reframe os sofrimentos causados no contexto do trabalho (Dejours, 2008; Bendassolli \& Soboll, 2011; Mendes \& Araújo, 2011).
Nos últimos anos, há vários registros, no Brasil, de estudos e pesquisas sobre o desenvolvimento das doenças psíquicas no trabalho e suas respectivas relevâncias e impactos psicossociais na vida dos trabalhadores (Alves, 2011; Franco, Druck \& Seligmann-Silva, 2010; Guimarães, Jorge \& Assis, 2011; Jorge et al, 2007; Jilou, 2013; Moreira, 2014; Teixeira, 2012). Nesse contexto, destaca-se aqui o Transtorno de Estresse Pós-Traumático (TEPT) que vem crescendo de forma alarmante (Bucasio et al, 2005; Franco, Druck \& Seligmann-Silva, 2010; Knapp \& Caminha, 2003). Quando os sujeitos desenvolvem o TEPT, as organizações oferecem tratamentos superficiais, lineares e/ou assistencialistas aos trabalhadores adoecidos, quando não demitem ou afastam eles de suas atividades laborais sem os devidos cuidados psicológicos necessários para suportarem o sofrimento de forma digna e humana. Essa situação denuncia, assim, estratégias precárias para lidar com as limitaçóes do trabalho e não oferecem um tratamento psicológico capaz de criar condiçóes dos sujeitos reframe, transformarem os sofrimentos em atividades orientadas para saúde mental dos adoecidos 
(Câmara-Filho \& Sougey, 2001; Dejours, 2013; Faria \& Dalbello-Araujo, 2011).

De acordo com o discurso neoliberal, frente ao contexto do trabalho dinâmico e instável da atualidade, é necessário ser flexível. Para enfrentar suas crises, reduzir custos e ampliar o número de empregos, sendo "flexível", matem-se, também, a precarização (Moreira, 2014), pois se beneficia as produçóes dos mercados e serviços, às custas de redução de direitos trabalhistas, aumento de jornadas de trabalho, criação de metas inalcançáveis e o próprio trabalho humano se coisifica. O homem se torna em uma mercadoria.

À medida que os sujeitos trabalhadores precisam se esforçar, ultrapassar seus limites e corresponderem às expectativas organizacionais, as próprias organizaçoes se transformam em contextos "desumanos" ao negar condiçôes dignas e justas de trabalho. Tornam-se ambientes mais vulneráveis a acidentes, violências simbólicas e aumento do risco de desenvolver o TEPT; desvalorizando o trabalho humano, gerando insegurança, instabilidade e desamparo no trabalho (Franco, Druck \& Seligmann-Silva, 2010) e diminui-se a qualidade da saúde psíquica do trabalhador (Teixeira, 2012). Isso evidencia um problema ético-politico que é um campo fértil para atuação dos profissionais da Psicologia que defendem a perspectiva teórica e metodológica da clínica psicodinâmica do trabalho.

\section{Psicopatologias no trabalho precarizado}

A precarização no trabalho é concebida como um processo multidimensional constituído pelo desrespeito às conquistas históricas das manifestaçóes sociais, políticas públicas e direitos trabalhistas. Além disso, degrada o ambiente de trabalho, privando os sujeitos de terem acesso à educação, saúde e condiçóes de trabalho digno que acabam gerando psicopatologias e violência social e alteram a vida dos sujeitos trabalhadores de forma negativa tanto dentro quanto fora do trabalho (Faria $\&$ Dalbello-Araujo, 2011; Saltini, Vidal, \& Oliveira-Sobrinho, 2014). Em defesa de um mundo melhor, mais ágil, mais confortável, há a necessidade da maximização da competitividade no mercado de produtos e serviços, pautadas em uma lógica fordista/toyotista de produtividade/qualidade total. Assim, a perfeição se torna uma marca de um avanço no mercado de trabalho da contemporaneidade. Mas questiona-se aqui a que preço (Franco, Druck \& Seligmann-Silva, 2010).

No cenário internacional, não há dúvidas dos avanços de mobilizaçôes sociais, trabalhistas, industriais e urbanos durante e após a $2^{\mathrm{a}}$ grande guerra mundial que foram decorrentes de estratégias do sistema capitalista, com destaque da Era de Ouro nos EUA entre os anos de 1940 e 1970 e o Estado de Bem-Estar Social, na Europa, entre os anos de 1950 e 1970. No Brasil, também há registros de mudanças significativas dos mesmos avanços, com o destaque da Era Vargas (1930-1945) e seus desdobramentos até a constituição de 1988 (Hobsbawm, 1995).

Porém, Moraes (2008) argumenta que após as transformações políticas e econômicas a partir da década de 70 , o mercado de trabalho, munido de novas demandas de tecnologias, produtos e serviços, exige novas estratégias de manter e avançar os contratos e direitos trabalhistas. Trata-se da flexibilização. Após a crise da sociedade fordista dos anos 70, marcada pelo aumento significativo de desemprego e pobreza em vários países do mundo, a saída encontrada pelo sistema político neoliberal estava em uma forma de gestáo flexível. Desde então, o conceito de precarização do trabalho ganha destaque nas ciências humanas, inicialmente e principalmente na França (Junqueira et al, 2010; Castel, 2009). Flexibilização essa que é, na verdade, uma estratégia administrativa que só possui uma conjuntura, uma superfície nova, uma vez que advém das teorias de Adam Smith (1723-1790), que foram aperfeiçoadas por Taylor (1856-1915) e colocadas em prática pelo Ford (1863-1947) e posteriormente, reelaboradas pelo Toyotismo.

O trabalho, dessa forma, é reorganizado. São iniciadas "novas" formas de negociar, de estabelecer as jornadas de trabalho, de recompensar, de oferecer garantias, etc, com o intuito de diminuir os gastos, aumentar o lucro e a produtividade com "perfeição" de forma ajustável/flexível às demandas dos negócios vigentes, dignos da atenção de investidores e/ou consumidores. Surge, então, uma nova ordem neoliberal globalizante.

O impacto das mudanças das reformas trabalhistas (Alves, 2011) é caracterizado pela precarização da saúde dos trabalhadores com ênfase no desenvolvimento de diferentes psicopatologias do trabalho, com o TEPT (Stock, Barbosa \& Kristensen, 2014). Franco, Druck \& Seligmann-Silva (2010), entre outros, corroboram com essas afirmaçôes e argumentam que há uma vulnerabilidade em massa que legitima uma precarizaçáo social decorrente de tal configuração trabalhista resumidas na flexibilização e acrescentam as pesquisas voltados para a Saúde Mental Relacionada ao Trabalho (SMRT) e sua relação com a precarização do trabalho, fundamentados em estudos clínicos e sociais, nas últimas 3 décadas, em vários países, incluído o Brasil, e destacam as seguintes psicopatologias: quadros depressivos, dependência de bebidas alcoólicas e 
psicotrópicos, Burnout e o TEPT (Alves, 2011; Franco \& Seligmann-Silva, 2010; Guimarães; Jorge et al, 2007; Jilou, 2013; Moreira, 2014; Stenger et al, 2014; Stock, Barbosa \& Kristensen, 2014).

\section{TEPT: características e formas de tratamento}

O TEPT é definido, de acordo com o DSM V (APA, 2013), como um conjunto de sintomas nos quais os sujeitos vivenciam, testemunham, ouviram falar ou foram confrontados com algum acidente ou em contingências nas quais tiveram morte, ferimentos graves, ameaça à integridade física da vítima ou de outras pessoas cujos resultados se revelam em forma de intensa carga afetiva/ psicológica, alteraçóes negativas persistentes em cogniçóes e humor e/ou. Araújo \& Lotufo-Neto (2014) acrescentam que aqueles que são frequentemente expostos a detalhes aversivos de eventos traumáticos como, por exemplo, socorristas recolhendo restos humanos ou policiais repetidamente expostos aos detalhes de um abuso infantil, ou ainda, o sujeitos exeprenciarem condiçóes não dignas e humanas de trabalho, não terem seus direitos atendidos, tendo que lidar, repetidamente, com a precarizaçáo do trabalho. Porém, "vale ressaltar que esse critério não se aplica à exposição através de mídia eletrônica, televisão, filmes ou imagens, a menos que esta exposiçáo seja relacionada ao trabalho" (p. 76).

Em 2012, foram registrados 7.892 casos de acidentes de trabalho no trabalho no Brasil, entre os trabalhadores da Providência Social, em 2013, 8.989, ambos os registros de casos no grupo de reaçóes ao stress grave e transtornos de adaptação (F43), entre os quais encontra-se o TEPT (F43.1), de acordo com Ministério da Previdência Social (2014).

Nota-se que houve um aumento ao longo do tempo desse grupo de estresse. Todavia, esses registros só incluem somente aqueles que possuem carteira assinada, de acordo com as leis trabalhistas do Brasil, deixando de lado vários outros grupos e categorias de trabalho de fora como militares, outros servidores públicos, autônomos, comerciantes informais, entre outros; sugerindo que a quantidade de sujeitos diagnosticados com o TEPT seja maior. Ou seja, essas informaçóes podem estar aquém da realidade, principalmente pelo fato de muitos transtornos mentais não serem devidamente registrados. Há, ainda, os casos denominados de "outros" (150624 pessoas em 2012 e 151176 pessoas em 2013) no qual não se sabe se foi de ordem física ou psicológica. Dificultado o controle da possível associação das doenças psíquicas no trabalho e, ao mesmo tempo, sugerindo o possível aumento do registro estatístico das doenças psíquicas no trabalho que justificam o desenvolvimento do TEPT devido à precarizaçáo.

Segundo o DSM V (APA, 2013) o TEPT é desencadeado a partir de vários eventos estressores traumáticos como, por exemplo: sequestro, assalto à mão armada, desastres naturais ou causados pelo homem, acidentes automobilísticos graves, tortura, ataque sexual ou físico, entre outros. É comum o sujeito com o TEPT reviver, simbolicamente, o evento traumático de forma contínua e ter episódios de excitabilidade aumentada durante o período de tempo superior a um mês (APA, 2002; 2013). Além disso, causa sofrimento que impacta significativamente nos diferentes papéis sociais que o sujeito possui, nas suas relaçóes pessoais e profissionais, comprometendo a sua saúde psicológica. Ainda, é comum notar que os sujeitos com TEPT desenvolverem comportamentos de hipervigilância, não se interessam em manter atividades que eram fontes de prazer para eles, reduzem intensamente a interação e frequência de contatos com as pessoas e dificuldades para dormir (Câmara-Filho \& Sougey, 2001; Knapp \& Caminha, 2003).

O diagnóstico pode ser confuso, inadequado/não apropriado, pois muitas vezes o TEPT é confundido com outras doenças e transtornos e/ou há o fenômeno da comorbidade, ou seja, ter duplo diagnóstico ou mais de dois transtornos agregados: além do TEPT pode haver, simultaneamente, outros transtornos (Câmara-Filho \& Sougey, 2001; Knapp \& Caminha, 2003; Ouimette, Read, Wade \& Tirone, 2010; Schaefer, Lobo \& Kristensen, 2012). Diante dos malefícios afetivos e físicos do TEPT há, ainda, conseqüências sociais e econômicas significativas que interferem nos relacionamentos e atividades ocupacionais devido a possíveis momentos de evitaçáo, retraimento social, agressividade, entorpecimento, dentre outros. Assim, conforme Berninger et al (2010), World Health Organization (1998) o TEPT está diretamente ligado ao trabalho e o impacto da precarização do trabalho pode acarretar a diminuiçấo do prazer e saúde no trabalho (Mendes, 2007).

Usando o método de revisóes sistemáticas de Ensaios Clínicos Randomizados (ECR), Soares e Lima (2003) argumentam que há várias maneiras de lidar com o TEPT. Dessa forma, os autores (2003, p.63) encontraram e listaram diferentes intervençôes psicoterápicas e psicossociais para o tratamento do TEPT. Saltini, Vidal \& OliveiraSobrinho (2014); Ghizone e Mendes (2014), porém, acrescentam que são tratamentos lineares e assistencialis- 
tas, de acompanhamento dúbio, sem iniciativa que integra as políticas organizaçôes de gestão da saúde psíquica dos trabalhadores e, tanto na forma de diagnosticar, quanto tratar as psicopatologias no trabalho, possui um viés unidimensional da saúde: a perspectiva médico-farmacológica.

São exemplos de intervençôes psicoterápicas e psicossociais para o tratamento do TEPT no ECR de Soares e Lima (2003): a terapia cognitivo-comportamental; Eye movement desensitisation and reprocessin; Manejo afetivo; psicoterapia psicodinâmica (com base psicanalítica freudiana clínica e não na Clínica psicodinâmica do trabalho ) [grifo nosso]; Hipnoterapia; Relaxamento e intervençôes farmacológicas. Soares e Lima (2003) e Knapp e Caminha (2003) revelam que todas elas mostraram-se efetivas no controle do transtorno. Porém, perceberam um retorno mais significativo na terapia cognitivo-comportamental com um resultado de metanálise mostrando uma taxa de melhora em torno de $90 \%$ ao fim do tratamento e $85 \%$ em seis meses de seguimento. Tal resultado é contestado pelos estudos de Meshulam-Werebe, Andrade e Delouya (2003) e Vieira-Neto (2004), demonstrando que alguns tipos de TEPT respondem pobremente a terapias cognitivo-comportamentais e ao tratamento psicofarmacológico. Pacientes que desenvolvem o TEPT complexo beneficiamse de terapias psicanalíticas. Porém, Soares e Lima (2003) argumentam que estudos bem conduzidos e com outras abordagens devem trazer melhorias no conhecimento para lidar com a evolução do TEPT. Não se tem registro, assim, de como que a Clínica psicodinâmica do trabalho poderia contribuir para lidar com o fenômeno do TEPT experenciado no contexto do trabalho. Especialmente diante das atuais demandas e configuraçóes do trabalho flexível e precarizado da atualidade.

\section{TEPT no trabalho e a Clínica psicodinâmica do trabalho}

A Clínica psicodinâmica do trabalho se insere em um campo de teorias críticas, cujo foco é compreender a mobilização subjetiva no trabalho. Mobilização essa que é entendida como um engajamento afetivo, um modo singular dos sujeitos agirem e pensarem. Esses processos se manifestam pelos modos de gestáo individual e coletiva do trabalho nas dimensóes visíveis e invisíveis da organizaçáo do trabalho prescrito e do trabalho real, no qual potencialmente os sujeitos podem emancipar, reframe o sofrimento e transformar a organizaçáo do trabalho em uma fonte de prazer e de saúde. O prazer e a saúde dizem respeito a uma construção intersubjetiva que integra o psíquico e o social de modo indissociável no trabalhar, no fazer, na expressão da subjetividade, no coletivo de trabalho e nos modos como as relaçóes de trabalho se constroem, produzindo um jogo de forças e uma dinâmica própria aos contextos de trabalho. Para tanto, utiliza-se da palavra que no processo da clínica do trabalho é possível compreender as contradiçóes entre o trabalho prescrito e o trabalho real (Mendes \& Duarte, 2013).

Trabalhar vai além do concreto do trabalho. É preencher a lacuna entre o prescrito e o real e essa experiência é constitutiva da subjetividade do sujeito no qual o trabalho se torna central em sua constituiçáo e, isso, pressupóe um sofrimento de caráter dúbio: pode ser criativo ou patogênico (Dejours, 2013). Segundo Mendes e Duarte (2013) o sofrimento é criativo quando há inteligência prática por parte do sujeito, sabendo inovar diante do imprevisto, ou seja, quando move o trabalhador a buscar soluçóes para seu trabalho, podendo vivenciar, assim, gratificação e prazer. Quando a mobilização leva a paralisação frente ao real, envolvendo a angústia, fatores estressores, medo e insegurança, a experiência do sofrimento criativo transforma-se em sofrimento patogênico.

Frente às novas formas de organização do trabalho, o sofrimento patogênico é o que mais tem se intensificado e se revelam como um modo de dominaçáo social muito mais sofisticado e difícil de ser identificado. Mediante a flexibilização do capital, percebe-se a precarização do trabalho marcado por patologias sociais (Faria \& DalbelloAraujo, 2011; Heloani \& Lancman, 2004; Martins \& Mendes, 2012; Mendes \& Araújo, 2011). Além dos acidentes e possibilidade de lesôes que comprometem a saúde do corpo há, também, as doenças de ordem psicológica que são desenvolvidas quando o trabalhador vive situaçōes que envolvam estresse e sobrecarga de trabalho, assédio, suicídio, normopatias, sociopatias, drogadição, o TEPT, dentre outras. Assim, o sofrimento se apresenta como uma reação, uma manifestação da resistência e da insistência em viver em ambiente precarizado, que se desdobra como um mobilizador para luta contra as patologias sociais (Lancman \& Jardim, 2004; Mendes \& Araújo, 2012).

Diante de tamanha complexidade, dentro das atividades que comprometem a saúde física e psicológica do trabalhador o estresse é bastante enfocado, provocando lesôes corporais, perturbação funcional, redução da capacidade para o trabalho de caráter temporário ou permanente e, em casos mais extremos, até a morte (Lei no 8.213 Brasil, 1991).

Apesar do TEPT não ser um fenômeno exclusivo de certas categorias de trabalho, Schaefer, Lobo e Kristensen, (2012) registraram e pontuam em suas pesquisas que os 
casos mais frequentes foram com os profissionais da saúde como médicos e enfermeiros (entre outros); em policiais, bombeiros e bancários.

Acrescenta-se aqui a Lei 8.213; artigo 19 (Brasil, 1991) na qual descreve o acidente de trabalho, ou relacionado ao trabalho, o fenômeno no qual ocorreu diretamente para ocorrência da lesão física ou perturbação psicológica sofridos no local e horário de trabalho. Dessa forma, o sujeito que experencia um evento traumático no ambiente do trabalho durante sua jornada pode ser caracterizado um acidente de trabalho, gerando sofrimento e repercutindo negativamente tanto na vida pessoal do sujeito quanto na profissional. Assim, frente aos diferentes desafios e perspectivas em relaçấo ao TEPT, apresenta-se a aqui a tese de que a Clínica psicodinâmica do trabalho contribui para ressignificação do TEPT como consequente de precarização no trabalho, promovendo saúde psíquica ao trabalhador adoecido, criando condiçôes para ele retomar suas atividades cotidianos e, potencialmente, desenvolver novos sentidos para sua condição de sujeito em seus múltiplos papéis sociais e contextos que ele possa interagir.

\section{Método da Clínica psicodinâmica do trabalho}

A Clínica psicodinâmica do trabalho é o espaço da escuta e da fala do trabalhador na qual possibilita construir e reconstruir, resgatar e potencializar a mobilização subjetiva no cotidiano do coletivo de trabalho (Bendassolli \& Soboll, 2011). É momento de tornar visível o invisível das relaçóes entre a organização do trabalho e a mobilização subjetiva; desvelar/revelar o sofrimento, as defesas, as patologias e construir novos destinos para o sofrimento mais próximos da saúde mental e da melhoria da qualidade do trabalho (Louzada \& Oliveira, 2013).

Concebe-se que o sofrimento náo deve ser tomado como patologia, mas como um alerta para que açóes sejam mobilizadas; ele se transforma em patologia quando o processo de ressignificação é fracassado. A clínica, dessa forma, promove o lugar da autonomia, criação e negociação. Desenvolve meios de construir estratégias saudáveis para mediar o sofrimento, ressignificá-lo, ou seja, elaborar, sublimar, transformar o sofirmento em vivência de prazer (Mendes \& Araújo, 2012). É nesse sentido que está a relevância, a importância de a Clínica psicodinâmica do trabalho, na qual há o espaço da escuta clínica do sofrimento na ressignificação do TEPT. Assumindo tal perspectiva, cria-se condiçóes de resgatar a capacidade de elaborar e pensar ao partilhar o sofrimento, a angústia, o medo, a insegurança proveniente da relaçáo do trabalhador com a organizaçáo e do trauma vivido no trabalho (Bendassolli \& Soboll, 2011).

A proposta da psicodinâmica do trabalho na "modalidade" clínica surgiu com Dejours (2008). Mendes e Araújo (2012), a partir de tal proposta de Dejours (2008), elaboram uma perspectiva diferenciada, com o conceito da escuta clínica da psicodinâmica do trabalho: uma prática que inclui a pesquisa e a intervenção como dimensōes indissociáveis. No espaço de discussão é privilegiada a palavra (instrumento); a fala/escuta entre os sujeitos pesquisados e o pesquisador. Isso exige uma qualificação teórico-metodológica que articule uma teoria do sujeito e uma teoria social a uma condução centrada na escuta do outro. Uma escuta ao não dito, ao oculto, ao silenciado, buscando/construindo junto com o coletivo, novas estratégias para reframe o sofrimento, atribuindo um novo sentido ao trabalho (Ghizone \& Mendes, 2014; Martins \& Mendes, 2012; Medeiros, 2012; Mendes \& Araújo, 2012).

Análise dos dados: inicialmente Mendes e Araújo (2012) argumentam que há cinco dispositivos da escuta clínica: 1-A demanda: diz respeito aos indivíduos ou grupos de trabalhadores adoecidos que buscam o pesquisador com formação em Clínica psicodinâmica do trabalho , que é o pesquisador-clínico, com o intuito da ressignificação da saúde dos sujeitos com o TEPT. Tal demanda depende de esclarecimentos técnicos, éticos e políticos próprios de acordo com o contexto histórico, social e cultural dos integrantes e da organização na qual eles trabalham, pontuando o caráter não assistencialista da clínica. E sim instrumentalizar os trabalhadores a serem protagonistas no seu ambiente profissional.

2-A elaboração e perlaboração: a elaboração consiste no processo no qual a clínica, a partir da escuta/fala dos trabalhadores e do pesquisador-clínico, criará condiçôes para os sujeitos organizarem e estruturarem seus afetos, estimulando o potencial de reframe seu próprio trabalho de forma mais criativa e saudável. A perlaboração é um processo longo que permite o sujeito a aceitar certos elementos recalcados e libertar-se da influência da repetição. $\mathrm{Na}$ elaboração e perlaboração o sujeito sai do relembrar para reescrever uma história.

3-A construção de laços afetivos: no cenário rico para que os afetos sejam nomeados, o papel do pesquisadorclínico é tornar-se, na escuta, um elo entre todos os participantes, possibilitando a reumanização do sofrimento diante da precarização e desumanização vividas e possi- 
bilitar que o sujeito construa no coletivo novos sentidos e torne a sua realidade suportável.

4-A interpretação: é o processo no qual dá forma ao que é vivido/trazido pelos trabalhadores. É dar significado à fala, perceber as relaçóes de prazer e sofrimento, os gestos, as relações de poder; é a experiência e os referenciais teóricos e metodológicas dos clínicos, etc., que possibilitem a compreensão dos pesquisadores-clínicos externos sobre os diferentes elementos que constituem a singularidade da instituição e dos trabalhadores investigados.

5-A formação do clínico: o clínico é indispensável da condução clínica. Sua própria subjetividade constitui o próprio método. Assim, a formaçáo do clínico não é somente técnica, mas ética e afetiva. Fazer a clínica envolve o sofrimento diante do real, o que requer condiçôes profissionais e institucionais para mobilização subjetiva do clínico. Sem essas condições, é muito difícil o engajamento entre a fala e a escuta.

As condições para fazer a clínica são: organização da pesquisa, construção e analise da demanda; instituição das regras de conduta do coletivo de pesquisas e do coletivo; constituição do espaço da fala e da escuta; estruturação do memorial; restituição e deliberação; diário de campo e registro dos dados; supervisão; apresentaçáo dos relatos e avaliaçãoo (Mendes \& Araújo, 2012).

O processo dessas condições se dá pela caracterização política, histórica, social e econômica do campo do local e sujeitos pesquisados por algum tipo de psicopatologia e/ou sofrimento no trabalho (Martins \& Mendes, 2012). Há ainda o uso de instrumentos, escalas e questionários dentro da perspectiva da psicodinâmica do trabalho como o Protocolo de Avaliaçáo dos Riscos Psicossociais no Trabalho (PROART - Facas, 2013), por exemplo. Após todas as condiçóes, locais, regras pautadas na ética em pesquisa estiverem prontas, o pesquisador-clínico analisa e negocia com a demanda a quantidade de participante (individual ou grupos de no mínimo 6 e no máximo 12 pessoas, geralmente) e sessóes necessárias (em torno de 10). Toda sessão é grava em áudio. $O$ áudio passa por uma técnica de análise clínica do trabalho que analisa a rede de significados e sentidos que são construídos na relação do pesquisador-clínico com os sujeitos e entre os próprios sujeitos que compartilham seus sofrimentos. Os conteúdos/dados são armazenados em forma de relatório de campo, supervisionado por um pesquisador clínico mais experiente, e, cada sessão, se transforma em um memorial que é lido antes de começar a sessão seguinte. Após o término da sessão, todo o processo é avaliado, retornado para os participantes e, quando possível, divulgado para a comunidade acadêmica.

\section{Considerações finais}

A flexibilização do trabalho legitima a precarização do trabalho, aumentando ainda mais a chance de gerar psicopatologias graves, como o TEPT, no contexto do trabalho. O presente ensaio mostrou como a Clínica psicodinâmica do trabalho pode criar condiçóes para a transformação do sofrimento patogênico, enfatizando o TEPT, que vem crescendo de forma alarmante no Brasil.

Uma vez que o mercado de trabalho prioriza interesses particulares embasados em aumentar o lucro e não a saúde psíquica do trabalhador, esse ensaio é uma denúncia pública. De forma crítica, articula e corrobora com diferentes estudos, demonstrando que o contexto do trabalho, historicamente, foi constituído por degradações e reduçóes sucessivas dos diretos trabalhistas e condiçôes dignas de trabalho, principalmente com o modelo de gestão vigente da flexibilização. Mostrado que o próprio Estado se tornou conivente com a precarização.

Esse cenário evidencia medidas urgentes de políticas públicas voltadas para transformaçóes psicossociais nas relaçôes de trabalho. Principalmente com o TEPT, cujas consequências do trabalho precarizado causam prejuízos irreversíveis na qualidade de vida profissional e pessoal dos que sofrem dessa categoria de estresse.

Nessa perspectiva, a clínica do trabalho tem contribuído para qualificar pesquisas epidemiológicas, considerando nos estudos, o sofrimento psíquico como eixo central para criação de políticas públicas preventivas para os adoecimentos em diversas categorias profissionais. Isso implica desprecarizar o sujeito. A simbolização do sofrimento permite o sujeito se tornar protagonista à medida que as açôes propostas resultam de experiências vividas e assumidas, diferente de assumir uma postura alienada e oprimida que se submete às tarefas prescritas tal como as recebe.

A política, dessa forma, sai de uma lógica programática para uma lógica das diferentes classes de trabalhadores e situaçóes. A questáo social passa a ser formulada em um espaço público, fortalecendo a postura do engajamento coletivo. Ela denuncia aos sujeitos a solução ideal e torna a realidade aceitável. Por fim, é importante ressaltar as questóes éticas envolvidas na clínica quando da atuação sobre o TEPT, o sofrimento humano e o adoecimento por causa da precarização do trabalho. E, por fim, Mendes e 
Araújo (2012), argumentam que o trabalho situa-se em uma dimensão da diversidade humana, capaz de respeitar as diferenças. $\mathrm{Na}$ Clínica psicodinâmica do trabalho a interpretação das defesas coletivas é feita sem fazer dela um ato de violência, pois se requer do pesquisador-clínico intensa responsabilidade já que tal processo de fala/escuta do sofrimento implica inúmeras consequências na subjetividade dos envolvidos. "Busca-se uma fala verdadeira e a realização, pelo sujeito, de sua história em relação a um futuro, diminuindo o abismo do reconhecimento entre seu afeto e a emissão das suas palavras" (Mendes \& Araujo, 2012, p.135). Atualmente, a equipe de pesquisadores do Labortório de Psicodinâmica e Clínica do Trabalho (LPCT) da Universidade de Brasília (UnB) está desenvolvendo o trabalho da escuta do sofrimento de trabalhadores que desenvolveram TEPT no contexto de trabalho. Os trabalhadores estão em processo de ressignificação do sofrimento e, alguns, já tiveram sucesso de ressignificação do sofrimento. Quando oportuno, detalharemos os resultados em próximas publicaçóes.

\section{Referências}

Alves, G. (2011). Trabalho flexível, vida reduzida e precarização do homem-que-trabalha: perspectivas do capitalismo global no século XXI. In: Vizzaccaro-Amaral, A. L., Mota, D. P. \& Alves, G. (Orgs). Trabalho e saúde: a precarização do trabalho e a saúde do trabalhador no século XXI. São Paulo: LTR. Retirado de: http://www.proceedings.scielo.br/pdf/sst/n8/02.pdf

American Psychiatry Association (2013). Diagnostic and Statistical Manual of Mental disorders - DSM-5. 5th.ed. Washington: American Psychiatric Association.

Aquino, C. A. B. (2008). O Processo de precarização laboral e a produção subjetiva: um olhar desde a psicologia social. $O$ Público e o Privado, (Vol. 11), 169-178. Retirado de:http:// seer.uece. br/?journal=opublicoeoprivado\&page=article\&o p=view\&path[]=140\&path[]=211

Araújo, A. C. \& Lotufo-Neto, F. (2014). A Nova Classificação Americana Para os Transtornos Mentais-o DSM-5. Revista Brasileira de Terapia Comportamental e Cognitiva, 16 (1), 67-82. DOI: ISSN 1982-3541.

Associação Americana de Psiquiatria -APA (2002). Manual diagnóstico e estatístico de transtornos mentais (4ª . Ed.). Porto Alegre: Artmed.

Bendassolli, P. F. \& Soboll, L. A. P. (2011). Clínica do trabalho. Cadernos de Psicologia Social do Trabalho, 14(1), 59-72.

Berninger, A., Webber, M. P., Cohen, H. W., Gustave, J., Lee, R., Niles, J. K., ... Prezant, D. J. (2010). Trends of elevated PTSD risk in firefighters exposed to the World Trade Center disaster: 2001-2005. Public Health Reports, 125, 556-566.
Bucasio, E., Vieira, I., Berger, W., Martins, D., Souza, C., Maia, D., ... Jardim, S. (2005). Transtorno de estresse póstraumático como acidente de trabalho em um bancário: relato de um caso. Revista de Psiquiatria do Rio Grande do Sul, (Vol. 27), 86-89.

Buodo, G., Ghisi, M., Novara, C., Scozzari, S., Di Natale, A., Sanavio, E., Palomba, D. (2011). Assessment of cognitive functions in individuals with post-traumatic symptoms after work-related accidents. Journal of Anxiety Disorders, (Vol. 25), 64-70. DOI: 10.1016/j.janxdis.2010.08.004.

Câmara-Filho, J. W. S. \& Sougey, E. B. (2001). Transtorno de estresse pós-traumático: formulação diagnóstica e questóes sobre comorbidade. Revista Brasileira de Psiquiatria, 23(4), 221-228.

Castel, R. (2009). La montée des incertitudes: travail, protections, statut de l'individu. Paris: Seuil.

Dejours, C. (2008). A metodologia em psicopatologia do trabalho. In S. Lancman, L. Sznelwar (Orgs.) Christophe Dejours: da psicopatologia à psicodinâmica do trabalho. (2aed., PP. 107-128). Rio de Janeiro: Fio-cruz/Brasília: Paralelo 15.

Dejours, C. (2013). A loucura do trabalho: estudo de psicopatologia do trabalho. (5a ed. ampliada/15a reimpressáo). Sáo Paulo: Cortez.

Druck, G. (2011). Trabalho, precarização e resistências: novos e velhos desafios?. Caderno CRH, 24 (1), 155-170. Retirado de: http://www.scielo.br/pdf/ccrh/v24nspe1/ a04v24nspe1.pdf

Facas, E. (2013). Protocolo de Avaliação dos Riscos Psicossociais no Trabalho - Contribuiçôes da Psicodinâmica do Trabalho. Tese de doutorado do Instituto de Psicologia da Universidade de Brasília - DF.

Faria, H. X. \& Dalbello-Araujo, M. (2011). Precarização do trabalho e processo produtivo do cuidado. Mediaçóes, 16 (1), 142-156.

Fernandes, R. C. P. (2011). Precarização do trabalho e os distúrbios musculoesqueléticos. Caderno CRH, 24 (1), 155-170.

Franco, T., Druck, G. \& Seligmann-Silva, E. (2010). As novas relaçóes de trabalho, o desgaste mental do trabalhador e os transtornos mentais no trabalho precarizado. Saúde Ocupacional, 35 (122), 229-248.

Ghizone, L. D. \& Mendes, A. M. (2014). Dispositivos para uma escuta clínica do sofrimento no trabalho dos catadores de materiais recicláveis. Contextos Clínicos, 7 (1), 15-26.

Guimarães, J. M. X., Jorge, M. S. B. \& Assis, M. M. A. (2011). (In)satisfação com o trabalho em saúde mental: um estudo em Centros de Atenção Psicossocial. Ciência e Saúde Coletiva, 16 (4), 2145-2154.

Heloani, R. \& Lancman, S. (2004). Psicodinâmica do trabalho: o método clínico de intervenção e investigação. Produção, 14 (3), 77-86. 
Hirata, H. (2011). Tendências recentes da precarização social e do Trabalho: Brasil, França, Japão. Caderno CRH, 24 (1), $15-22$.

Hobsbawm, E. J. (1995). A era dos extremos: o breve século XX (1914-1991). 2. ed. São Paulo: Companhia das Letras.

Jilou, V. (2013). Capitalismo flexível, trabalho precarizado e sofrimento psíquico de professores universitários. Uberaba, 1 (1), 187-201.

Jorge, M. S. B., Guimarães, J. M. X., Nogueira, M. E. F., Moreira, T. M. M. \& Morais, A. P. P. (2007). Gestão de recursos humanos nos centros de atenção psicossocial no contexto da política de desprecarização do trabalho no Sistema Único de Saúde. Texto Contexto Enfermagem, 16 (3), 417-425.

Junqueira, T. S., Cotta, R. M. M., Gomes, R. C., Silveira, S. F. R., Siqueira-Batista, R., Pinheiro, T. M. M. et al (2010). As relaçóes laborais no âmbito da municipalização da gestão em saúde e os dilemas da relação expansão/precarização do trabalho no contexto do SUS. Saúde Pública, 26 (5), 918-928.

Knapp, P. \& Caminha, R. M. (2003). Terapia cognitiva do transtorno de estresse pós-traumático. Revista Brasileira de Psiquiatria, 25(1), 31-36.

Lancman, S. \& Jardim, T. A. (2004). O impacto da organização do trabalho na saúde mental: um estudo em psicodinâmica do trabalho. Terapia Ocupacional-USP, 15 (2), 82-89.

Lei no 8.213, de 24 de julho de 1991 (1991, 24 de julho). Dispóe sobre os Planos de benefícios da previdência social e dá outras providências. Diário Oficial da União. Retirado de: http://www.planalto.gov.br/ccivil_03/LEIS/L8213cons. htm.

Louzada, R. S. M. L. \& Oliveira, P. T. R. (2013). Reflexóes sobre a metodologia de pesquisa em psicodinâmica do Trabalho. Revista Núcleo de Estudos Fenomenológicos [online], 5(1), 26-35. DOI: ISSN 2175-2591.

Martins, S. R. \& Mendes, A. M. (2012). Espaço coletivo de discussão: a Clínica psicodinâmica do trabalho como ação de resistência. Psicologia: Organizaçôes e Trabalho, 12(2), 171-184.

Medeiros, S. N. (2012). Clínica em psicodinâmica do trabalho com a unidade de operaçóes aéreas do DETRAN: o prazer de voar e a arte de se manter vivo. Dissertação de Mestrado. Instituto de Psicologia da Universidade de Brasília. Brasília-DF.

Mendes, A. M. \& Duarte, F. S. (2013). Notas sobre o percurso teórico da psicodinâmica do trabalho. In L. G. Freitas (Org.). Prazer e sofrimento no trabalho docente. Curitiba: Juruá.

Mendes, A. M.\& Araújo, L. K. R. (2011). Clínica psicodinâmica do trabalho : práticas brasileiras. Brasília, DF: Ex Libris.

Mendes, A. M.\& Araújo, L. K. R. (2012). Os dispositivos clínicos para escuta qualificada (pp. 39-64). In Clínica psicodinâmica do trabalho : o sujeito em ação. Curitiba: Juruá.
Meshulam-Werebe, D., Andrade, M. G. O. \& Delouya, D. (2003). Transtorno de estresse pós-traumático: o enfoque psicanalítico. Revista Brasileira de Psiquiatria, 25(1), 3740. DOI: ISSN 1809-452X. Retirado de: http://dx.doi. org/10.1590/S1516-44462003000500009.

Ministério da Previdência Social (2014). Recuperado em 01 de março de 2015 de http://www.previdencia.gov.br/wpcontent/uploads/2015/03/AEPS-2013-v.-26.02.pdf.

Moraes, P. R. S. (2008). Terceirização e precarização do trabalho humano. TST, 74 (4), 148-168.

Moreira, I. J. B. (2014). Prevalência de transtornos mentais comuns em trabalhadores da atenção primária à saúde e sua associação com fatores psicossociais do trabalho. Dissertação de Mestrado em Promoção da Saúde da Universidade de Santa Cruz do Sul - RS.

Ouimette, P., Read, J. P., Wade, M., \& Tirone, V. (2010). Modeling associations between posttraumatic stress symptoms and substance use. Addictive Behaviors, (Vol. 35), 64-67. DOI: 10.1016/j.addbeh.2009.08.009.

Saltini, M. R., Vidal, A. G \& Oliveira-Sobrinho, A. S. (2014). Políticas públicas de educação e precarização do trabalho em São Paulo: o abandono da profissão docente na Rede Pública Estadual. Trabalho e Educação, 23 (1), 99-117. Retirado de: http://www.portal.fae.ufmg.br/seer/index.php/trabedu/ article/view/1395.

Schaefer, L. S., Lobo, B. O. M. \& Kristensen, C. H. (2012). Transtorno de estresse pós-traumático decorrente de acidente de trabalho: implicaçóes psicológicas, socioeconômicas e jurídicas. Estudos de Psicologia, 17(2), 329-336.

Soares, G. O. \& Lima, M. S. (2003). Transtorno pós-traumático uma abordagem baseada em evidências. Revista Brasileira de Psiquiatria, 25(1), 62-67.

Stenger, E., Monteiro, M. I., Sabino, M. O., Miquilin, I. O. C. \& Corrêa-Filho, H. R. (2014). Lean production e riscos psicossociais: o caso de uma fusão multinacional de grupo metalmecânico no Brasil. Saúde Pública, 30 (8), 1765-1776.

Stock, T. O., Barbosa, M. E. \& Kristensen, C. H. (2014). Evidências de alteraçóes neurais na terapia cognitivo-comportamental: uma revisão da literatura. Contextos Clínicos, 7 (1), 27-36. Retirado de: http://revistas.unisinos.br/index. $\mathrm{php/contextosclinicos/article/view/ctc.2014.71.03.}$

Takahashi, M. A. B. C., Lacorte, L. E. C., Ceverny, G. C. O. \& Vilela, R. A. G. (2012). Precarização do trabalho e risco de acidentes na construção civil: um estudo com base na Análise Coletiva do Trabalho (ACT). Saúde Social, 21 (4), 976-988.

Teixeira, M. C. (2012). A invisibilidade das doenças e acidentes do trabalho na sociedade atual. Rdissan, 13 (1), 102-131. Retirado de: http://dx.doi.org/10.11606/issn.2316-9044. v13i1p102-131 
Vieira-Neto, O. (2004). Transtorno de Estresse Pós-Traumático em bancários vítimas de assalto ou seqüestro. Dissertação de Mestrado. Faculdade de Psicologia e Fonoaudiologia da Universidade Metodista de São Paulo. São Bernardo do Campo - SP.

World Health Organization. (1998). Enciclopedia de salud y seguridad en el trabajo. Edición española. Ministerio de Trabajo y Asuntos Sociales. Retirado de: http://www.insht. es/InshtWeb/Contenidos/Documentacion/TextosOnline/ EnciclopediaOIT/tomo4/sumario.pdf. 